\section{Extension Education
Methods}

\section{Greener Voices: An Exploration of Adult Perceptions of Participation of Children and Youth in Gardening Planning, Design, and Implementation}

\author{
Marcia Eames-Sheavly ${ }^{1,5}$, Kristi S. Lekies ${ }^{2}$, Leigh MacDonald ${ }^{3}$, \\ and Kimberly J. Wong ${ }^{4}$
}

ADDITIONAL INDEX wORDs. children, youth, youth development, garden-based learning, participation, ladder of participation, garden-based learning, youth engagement in planning

SUMMARY. This article discusses Greener Voices, a 3-year extension-research integration project intended to enhance the participation of children and youth in school- and community-based gardening settings and presents findings from a study of adult leaders' perceptions about the participation of children and youth at their sites. The project included six sites in New York and Pennsylvania consisting of rural, suburban, and urban settings; children at those sites ranged in age between 3 and 18 years. Over a 2 -year period, as part of the extension activity, sites were provided with consultation and written materials, a web site, and opportunities to attend a related workshop and conference. Interviews with adult leaders indicated moderate to high levels of participation at most of the sites, variation by age of participants and stage of project, the usefulness of a ladder of children's participation in raising awareness, barriers to participation, attitudinal and behavior changes, and positive impacts on the youth. Ongoing efforts are needed to assist sites/leaders, including strategies to expand thinking about the capabilities of children and youth, help children and youth adjust to new roles, and identity ways for younger children to increase their participation.

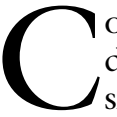

ommunity educators, teachers, designers, and parents consider the increase in children's

${ }^{1}$ Senior Extension Associate, Department of Horticulture, Cornell University, 169 Plant Science Building, Ithaca, NY 14853

${ }^{2}$ Assistant Professor and Extension Specialist, 4- $\mathrm{H}$ Youth Development, Ohio State University Extension, Columbus, $\mathrm{OH} 43210$

${ }^{3}$ Project Assistant for the Garden-based Learning Program, Department of Horticulture, Cornell University, Ithaca, NY 14853

${ }^{4}$ Graduate Assistant, Department of Communications, Cornell University, Ithaca, NY 14853

${ }^{5}$ Corresponding author. E-mail: ME14@cornell.edu. gardens in schools and communities an important and positive trend. Being active in children's gardens encourages positive attitudes toward nature and the environment (Lohr and PearsonMims, 2005; Skelly and Zajicek, 1998; Waliczek and Zajicek, 1999); enhances an awareness of the connection between plants and our food, shelter, clothing, and well-being (Heffernan, 1994); and can foster science, literacy, and social skills (Klemmer et al., 2005; Robinson and Zajicek, 2005; Waliczek and Zajicek, 1999). Children in many youth gardening projects take on horticultural tasks such as planting, weeding, and watering yet rarely participate in the planning, design, and other decision-making aspects of the project. Considering the numerous positive benefits of children's gardens, and the resources committed to this trend, exploring the most effective ways to engage children in the planning, design, and implementation of gardens is essential.

Many positive outcomes are also associated with increased participation, yet educators struggle with the challenges of including a youth voice. Children and youth participating in activities that include their input show increased feelings of competence and ownership, improved visibility in society, utilization of the unique contributions of this age group, and the fostering of important decision-making and critical thinking skills needed throughout life (Adams and Ingham, 1998; Willow, 2002). Garden projects benefit from the additional child and youth ownership, often with noticeably less vandalism, and enhanced overall care devoted to garden maintenance (Eames-Sheavly, 1999). However, many barriers prevent young people from wholly participating, most notably, time constraints and other challenges facing adult educators, beliefs regarding children's competence, and a lack of experience with this type of approach (Adams and Ingham, 1998; Driskell, 2002; Willow, 2002).

A significant barrier to children's participation was presented by Winter (1997), who stated that adults seek to shield children and serve as their helpers and protectors. Winter argues that an unfortunate side effect of this protection is that children are increasingly held inside a glass cage or special "youthland" and believes that society presents itself to youth as an anonymous quantity:

"...there 'will be' a playground in the neighborbood; an unused site 'is built upon;' there 'is' a new traffic plan for the district; usually with public consultation, but not with young people... who knows who the playgrounds in the neighborhood belong to, who is responsible for maintenance and bygiene, whom to turn to to get something done about insecurity on the streets...this is what the world looks like to the present generation; however smart they are, they do not count until maturity.” 
According to Winter, children have come to lack an understanding of the community framework and processes through which local change can take place. Protected from the "evils" of the adult world, children also are held back from the opportunity for civic involvement, including experiences that can help them to develop into independent, responsible, "engaged" adults. In Children's Experience of Place, Hart (1977) also articulates the developmental significance of the natural environment to the human as does Moore (1986) in Childhood's Domain. Moore and Young (1978) assert that children could be more directly involved in decision-making and environmental aspects of community development. Although working with children's ideas is not a panacea for designing ecologic, environmentally friendly landscapes, becoming involved in the process of garden planning, design, and implementation can be a way for children to learn about the environment on a local level. Participating in aspects of the process can provide young people with opportunities to become meaningfully involved in their communities as well as with their natural environment.

Arnstein (1969) created a "ladder" of citizen's participation looking at participation not as a discrete occurrence, but as a continuum. She saw participation as ranging from nonparticipation (through tokenism) to degrees of empowerment, which extended from therapy, informing, consultation, placation, partnership, and delegated power to, at the highest level, citizen control. Hart $(1992,1997)$ offers a modification of Arnstein's ladder with children as the participating citizens; eight rungs on the ladder represent the degrees of participation. These degrees are particularly significant because of the unique relationship of adults to children and the potential for using this relationship to the advantage of the adults.

The various levels of participation range from little to no participation or input on the part of children to projects fully initiated by children sharing decisions with adults. The levels are: 1) manipulation, 2) decoration, 3) tokenism, 4) assigned but informed, 5 ) consulted and informed, 6) adult-initiated with shared decisions with children, 7 ) child-initiated and directed, and 8) child-initiated with shared decisions with adults. At lower levels, children's opportunity to influence project direction or voice opinions is limited or nonexistent. They may participate in activities without knowing what they are about. At higher levels, children are able to make decisions about the course or outcome of the project, express opinions that are taken seriously, work collaboratively with adults, and be full participants and leaders in activity conceptualization, organization, and direction. The goal is to engage children to the greatest extent possible as determined by project activities, competencies required, and the developmental abilities and experiences of the children involved while realizing that it is not always possible or desirable to be at the very top of the ladder (Adams and Ingham, 1998; Hart, 1992, 1997) (Fig. 1).

Adult leaders of gardening sites may recognize the value of participation, particularly in the sustainability of a project or program, but feel perplexed as to how to involve children in planning, design, and implementation beyond the more familiar gardening activities. Faced with additional constraints of loss of funding, lack of time, and work-related stress, adult leaders in the Cornell University Cooperative Extension programs repeatedly mention feeling overwhelmed as to where to begin. As a result, helping adult leaders to identify the many ways young people can be meaningfully involved, as well as how to easily implement appropriate participation strategies, is essential.

This article presents findings from an evaluation of Greener Voices, a 3-year extension-research integration project intended to enhance the participation of children and youth in school- and community-based gardening settings. Interviews with adult leaders were conducted to learn more about the ways adult leaders perceived the participation of children and youth in the planning, design, and implementation of gardening projects. Recommendations for gardenbased learning projects are included.

\section{Materials and methods}

Participants. Participating sites consisted of an urban communitybased center, a rural and a suburban elementary school, a rural preschool center for children with disabilities, a rural child care center, and a rural cooperative extension program. Sites were recruited through the Cornell University Cooperative Extension electronic network of youth educators and through a colleague at a nearby university; the project leaders indicated through the electronic list that they wanted to identify several groups of adults interested in involving young people in the creation of outdoor projects such as children's gardens and ultimately to assist these groups and their youth partners in working together to plan and implement them. Other aspects of the Greener Voices project were included in the call for sites such as the opportunity interact with other sites, meet at a workshop, and to learn from a number of written and electronic resources. Funding allowed for approximately six sites to participate and the initial number of respondents was eight. Lack of funding and staff turnover at two additional sites, one urban and one rural, rendered them inactive during the course of Greener Voices. The sites varied from emergent to well-established and involved $\approx 250$ children and youth between the ages of 3 and 18 years.

Outreach activities. The Greener Voices approach involved a number of outreach activities, and adult project leaders were introduced to new ideas regarding participation over the course of 2 years. Activities included consultation to all site leaders on an ongoing basis, hosting a workshop for site leaders on youth gardening and participation, annual visits to all sites, developing a project web site, and providing books and materials on youth gardening and children's participation to the site leaders. Project staff recommended that adult site leaders read Children's Participation: The Theory and Practice of Involving Young Citizens in Community Development and Environmental Care (Hart, 1997), Changing Places: Children's Participation in Environmental Planning (Adams and Ingham, 1998), Creating Better Cities With Children and Youth: A Manual for Participation (Driskell, 2002), and Sowing the Seeds of Success (Eames-Sheavly, 1999). Several site leaders also attended the American Horticultural Society 


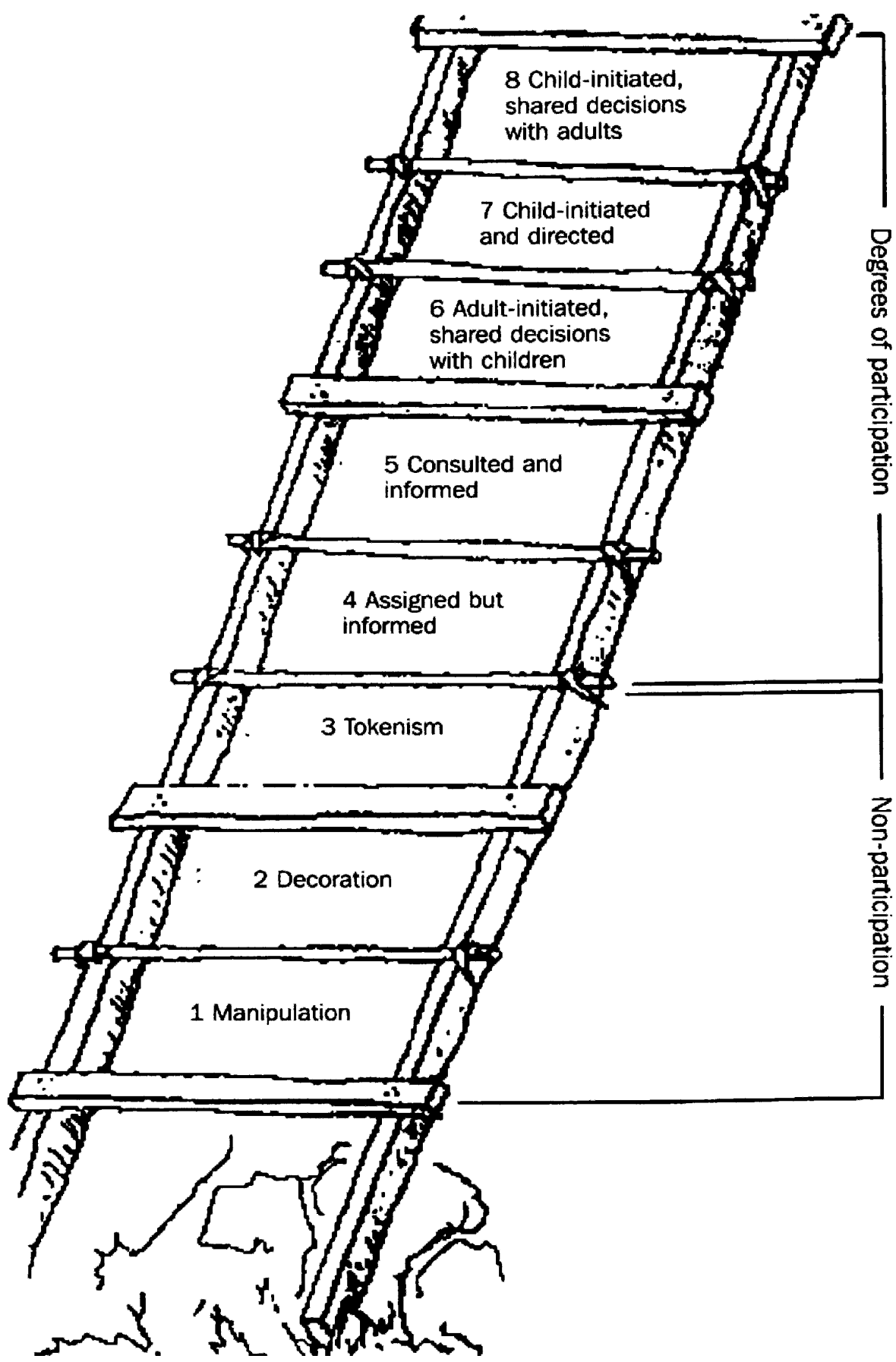

Fig. 1. The ladder of participation shows degrees of participation at the upper rungs and nonparticipation at the lowest three rungs. The figure is meant as a guide to adult facilitators wanting to establish situations that encourage groups of children to work at the level of their choosing (Hart, 1997).

Children and Youth Gardening Symposium at Cornell University in 2004.

A focus on the ladder of children's participation (Hart, 1992, 1997) is central to the Greener Voices project. Although this model is unfamiliar as a participation tool to many adult leaders in garden-based learning efforts, project staff adapted it for a gardening context and presented it people's competencies and how young people can contribute to programs and projects in a more engaged manner (Adams and Ingham, 1998; Hart, 1992, 1997; Holden and Clough, 1998).

In an effort to ground the ladder of participation in language recognizable to a gardening audience, the Greener Voices project team modified it to include additional text with concrete examples of garden-based learning activities at each rung of the ladder. At the decoration level, adults may quite literally "decorate" children. The example included is that children or youth may sport garden t-shirts with no involvement in organizing the program or understanding of the program. At the level of decoration, adults use children to bolster the program as if the children were understanding participants. Another example is having children sing garden songs at a harvest festival, and it may even appear that they wrote the song or that they were involved in organizing the garden or the festival when in fact they were not. At "tokenism," an example was included as having adults select charming, articulate youth to talk about the garden in a public venue but where youth have not had ample opportunity to reflect critically or consult with their peers. An example for "consulted and informed" described how a survey might be designed to gather young people's input into a school garden: children are informed of the purpose. They may be asked to volunteer and, afterward, they are fully informed of the results. With "childinitiated and directed projects," adults may notice a youth-led project emerging but allow them to occur in a youth-directed fashion. Hart places this second from the top rung on the ladder because occasionally young people do not trust adults enough to seek their input. The caution with this rung is in children carrying out their projects in secret resulting from fear of adults or because of intimidation by them. An example is a literally secret garden/landscape that adults do not know exists. At the top rung, "child-initiated, shared decisions with adults," young people feel sufficiently competent and confident in their role as community members to understand the need for collaboration, and that in asking adults for their input, 
the project may be strengthened. The key is that there is trust involved and that adults serve as listeners, observers, and sounding boards; they do not usurp with their own designs or attempt to take the organization of the project out of the hands of youth. For example, young people may determine that they want to clean up an old vacant lot in their community to create a nature trail. They learn about all aspects of creating such a trail, hold meetings to plan it, but control it with a friend's parent in local government, several parents, and a teacher with an interest in ecology for their diverse suggestions regarding certain aspects the project. All examples were derived from situations presented informally by cooperative extension staff and volunteers as well as American Horticultural Society Children and Youth Gardening Symposium participants over several years of conversations and working with the Cornell
University garden-based learning program. This helped to ensure that examples would be more likely to resonate with adult participants (Table 1).

INTERVIEWS AND ANALYSIS. Indepth interviews were conducted with 10 adult leaders at the six sites at the end of the 2-year period to learn more about their perceptions of the participation of children and youth in gardening activities. The interviews lasted $\approx 1$ to $1.5 \mathrm{~h}$ and consisted of questions regarding the specific gardening activities at each site, youth participation, the usefulness of the ladder of participation, barriers and challenges to participation, changes in participation, and impacts of participation. Greener Voices project leaders examined interview transcripts for key themes and lessons and then engaged in an iterative process of clarification and refinement regarding these themes and lessons.

\section{Results and discussion}

ChildREN's PARTICIPATION. At each site, children and youth were engaged in physical gardening activities such as planting. At most of the sites, children and youth were also involved in planning, discussions, decision-making, leadership roles, and problem-solving. Financial decisions, new participant training, activity evaluation, and reporting to funding providers occurred at two sites. At one site, youth served on an advisory board and were involved in developing publicity about the garden project.

When asked to describe their sites on the ladder of participation, leaders at one site indicated a " 4 " or "assigned but informed," two sites indicated " 6 " or "adult-initiated with shared decisions with children," one indicated both " 6 and 7 " or "adult-initiated with shared decisions with children" and "child-initiated and directed,"

Table 1. Specific garden-based examples, based on the ladder of participation, that were provided to site leaders to assist with an understanding of genuine participation.

- Child-initiated, sharing decisions with adults: Young people may determine that they want to clean up an old wooded hang-out area in their community to create a nature trail. They learn about all aspects of creating such a trail, hold meetings to plan it, but control it with a friend's parent in local government, several parents, and a teacher with an interest in ecology for their diverse ways of thinking about certain aspects of the project.

- Child-initiated and directed: Hart places this second on the ladder because occasionally young people do not trust adults enough to seek their input. The caution with this rung is in children carrying out their projects in secret because of fear of adults or being intimidated by them. An example is a literally secret garden or landscape that adults are not aware of.

- Adult-initiated, shared decisions with children: Children understand the breadth of issues, including fundraising, garden design, or organization and management, and they also understand how and why compromises are made, if they are necessary. They may also begin to cultivate a "language" of talking about this with others.

- Consulted and informed: A common example is a survey designed to gather young people's input into a school garden: children are informed of the purpose, they may be asked to volunteer, and afterward, they are fully informed of the results.

- Assigned but informed: Children are assigned to a school garden project and may not initiate the project themselves, but they are fully informed about all aspects of it, and it may even provide them with a sense of real ownership into the project. A key aspect of this rung is critical reflection, the degree to which children are engaged in it. Are children just viewed as a free source of help for the garden project or do they have a chance to reflect on it, consider it, and learn from it?

- Tokenism: The appearance of children's involvement is there, but in fact, they have had little choice about planning the garden project, communication around it, and no time in which to critically reflect and form their own opinions. Often, adults select charming, articulate youth to talk about the garden in a public venue, but those youth have not had ample opportunity to critically reflect or consult with their peers. The key with this "rung" is symbolic versus actual engagement and involvement.

- Decoration: Often involves, quite literally, decorating children; they may sport garden t-shirts with no involvement in organizing the program or understanding of the program. Adults may use children to bolster the program as if the children were understanding participants. Another example is having children sing garden songs at a harvest festival, and it may even appear that they wrote the song or that they were involved in organizing the garden or the festival, when in fact they were not.

- Manipulation: Adults consciously use children's voices to carry their own message about the gardening project. They may, for example, produce a garden poster, advertisement, or publication with drawings by children when children are not involved in the program planning. Another example is adults denying their own detailed involvement in meetings, planning, and shaping the project because they think it diminishes the effectiveness or impact of the project; they may say that children are genuinely engaged when engagement constitutes weeding or planting. Adults may design a garden, have kids do a simple planting, and then tell the local newspaper that children designed and built the garden. 
and one indicated going back and forth among 6,7 , and 8 "childinitiated with shared decisions with adults." A final site did not respond to this question but could be described as "assigned but informed."

ADULT PERCEPTIONS OF CHILDREN'S AND YOUTH'S ABILITIES. Perceptions of the abilities of children and youth varied significantly among the sites. At one extreme, a leader thought children were not fully capable of focusing, engaging, and planning. At the other, youth were described as competent and important members in the project, essential participants in planning and decisionmaking. Most site leaders, however, fell between these two extremes. Many expressed a desire for youth input and described engaging them to some degree. However, site leaders remained unsure about how to involve participants at multiple levels. Older children were generally perceived to be capable of higher levels of participation, which was reflected in their higher levels of actual participation.

Project stage. The stage of the project also impacted the degree of participation. For example, several sites asked children and youth to generate ideas about what the garden site might look like: what might be planted and what features such as seating and water to include. Typically this involved asking questions or having children and youth write down or draw ideas. Few sites, however, involved youth in garden preparation. Often seed was ordered, garden space determined, tools assembled, and soil prepared by adults in advance. Similarly, only one site reported youth participation in planning or advisory committees. A number of sites, however, noted that there would be more opportunities for children and youth involvement after the project was more established. Degree of participation was also relative to age; older youth were the most involved in decisionmaking.

USEFULNESS OF THE LADDER OF PARTICIPATION. The ladder of participation, as a tool, helped adult site leaders to become familiar with a new way of thinking about youth participation. As one leader indicated, "I guess I never had really thought about the possibility of having the kids be at that level in the planning process." All of the site leaders felt the ladder combined with examples specific to garden-based projects was useful. Site leaders commented that the ladder was easy to understand, it raised awareness, and it helped them realize children are capable of doing more than they perceived. Many mentioned that they referred to it regularly and one site leader shared it with the youth in the program. Another site leader indicated that, "It's just nice to know that there is a vocabulary for speaking about these things and that there is a whole spectrum of participation and that somebody's taken the time to really put that into levels." With respect to sharing decision-making, one site leader learned to question her actions: “Through the project, it's made me stop and think, can I give the decision-making power to the kids? Is this something that they can decide, and I shouldn't.... It's way too easy as an adult to just go ahead and plan and do." One leader provided specific examples of ways in which children were newly involved such as selecting varieties to plant and planning activities around food preparation, whereas another cited the creation of stepping stones, the shapes of the garden beds, and a new alphabet garden as projects entirely driven by young people.

Despite its usefulness, some site leaders found the vertical nature of the ladder daunting. The feeling that it is always necessary to be at the top could in turn influence leaders to falsely identify children and youth's level of participation as being higher than it actually was. As a site leader expressed, "I think that the only issue I sort of have with it is that it is a ladder, which in some ways gets people thinking it's a hierarchy and that we should always be at the top of the ladder.... We want the kids to have autonomy. It's not always appropriate for them to be at the top of the ladder, so just having a ladder as the metaphor kind of is confusing sometimes." Likewise, another site leader indicated "that the ultimate goal is not like you have to be at the top of the ladder all the time.... That was one of the things that was confusing when we tried to do it to the kids, too-is that they were, like, 'well, the top is the best and the bottom is the worst,' and we're like, 'well, sort of but not really...",

BARRIERS TO PARTICIPATION. Attitudinal barriers provided a challenge to participation, particularly the perception that children have little to contribute and need to be closely monitored. Identifying with this constraint, one site leader commented "we can't just let them run loose." Another leader discussed the challenge that "some kids are just never going to be interested in gardening and food systems issues," whereas she acknowledged that the way the program is structured is going to have a greater impact on interest than the content itself. Understanding participation remains a struggle for several sites, because commonly in children and youth programming, the term participation refers to the number of children enrolled in a program and the amount or duration they partake in an activity. Transcripts of interviews with site leaders indicated increased stammering and hesitation in speech during the participation questions compared with other types of questions with many ums, ahs, and repeat phrasing. This perhaps indicates lack of confidence around the topic, experiencing difficulty talking about it, or expressing their thoughts regarding participation.

Changes IN CHILdRen AND YouTH. Site leaders reported the children and youth adjusting to new roles over the course of the project. They were not used to having this level of power and autonomy: "I don't know if they're not used to it, or they just don't know what to say. Probably they're used to people saying, we're going to do this, and then they kind of can take the project and be creative within that, but actually coming up with what the project is or what they want to do, I don't know that they're used to that." Another adult leader said, "We have very high expectations of our kids and I think it takes a while for them to understand the level of participation that we want them to get to, in terms of giving them autonomy, because I think it's just foreign to them...at first they're like, 'You want me to do what? You want me to get on the phone and talk to somebody? I can't do that.' But then, they do it a couple of times, and they're like, 'ok, I can do that.' " Although site leaders rarely used the 
word "power," an adult indicated "it just takes a little while for them to get used to the idea of us wanting them to have power and autonomy.... and being serious about responsibility and having them come up with ideas and follow through." Lastly, one site leader pointed out that attaining certain levels of participation takes time, "Because all their lives, nobody's given them power to do anything. At first, they're like, 'What-?! You want me to make a decision and do something and-? Be in charge of it?' But once it clicks-it's the most rewarding thing, to see them, 'Oh, yeah, I can do this!' and 'I see this issue, and it's important to me, and I'm going to do something about it."

An elementary site volunteer commented on the shifts in leadership that began to take place as a result of the new approach to involving more youth in decision-making. She indicated that some students began taking a leadership role because of the magnitude of the project, and "when we saw that happening and realized what a big project it was, we (broke) them into groups and group leaders."

With the exception of one adult, it is clear that site leaders' thinking has changed as a result of Greener Voices. Changes in behavior were noted at some but not all sites. For example, at one site, "The original plan would have just been to do a design and have the kids participate in the implementation but not in the design." This site went on to engage children's ideas in a number of creative ways, including a voting booth that allowed entire grade levels of children to individually register their opinions about the garden project.

IMPACTS OF PARTICIPATION. Four of the site leaders described impacts they felt the children and youth experienced as a result of their participation in the gardening activities. All of these leaders mentioned greater enthusiasm for gardening-more involvement in gardening activities, excitement about planting and harvesting, a greater respect for plants, and an overall greater interest in gardening. As one leader described, "Some (of the youth) I can distinctly remember being very disinterested then (when the project started) are very much engaged now." Other impacts mentioned were more confidence in regard to gardening and in general, less shyness, increased social skills in working together with others, less stress and tension regarding statewide school assessment tests, changes in diet, taking a greater interest in the sources of food, and greater interests in the larger community. The other site leaders indicated the youth enjoyed gardening but felt their projects were either too small in scope or they did not spend enough time with the youth to note any impacts.

\section{Conclusion}

To increase the participation of young people in activities such as gardening, adults need training and support to change their beliefs about children's competencies and try new practices (O'Donoghue et al., 2002). Identifying ways for adults to become more inclusive of youth voice was an important goal of Greener Voices. The findings of this study have explored the perceptions of adult leaders toward the participation of children and youth at their gardening sites. Although a limitation of the study is the small number of sites and leaders interviewed, the results present some worthwhile lessons as a place to start for others working with children and youth in gardening activities.

Concern exists that young people have limited opportunities to engage in higher levels of participation and that young people are at risk of tokenism (Hart, 1997; O'Donoghue et al., 2002). In this study, four of the six sites described the participation of children and youth in activities at their sites as "adult-initiated, shared decisions with children" with two of these sites fluctuating between this and higher level "child-initiated" activities. Hart (1997) has indicated the importance of projects and programs being at the adult-initiated, shared decisionmaking level so that adults can foster a sense of competence and confidence among the youth they work with, eventually enabling the possibility of higher levels to be reached.

The site leader interviews clearly identified the youngest, preschoolaged children, as having the most limited opportunities for participation. Children of this age often were not viewed as capable of meaningful contribution and leaders who did view younger children as capable felt hindered by not knowing how to go about engaging them. Although leaders recognized the value of including young voices in decision-making, they requested assistance in finding ways to encourage young children to voice their opinions in appropriate ways. Driskell (2002) has suggested that the "limitations to children's participation are usually not their incapacity to understand and contribute, but adults' failure to discover ways to involve them." Therefore, adults should think of ways to support participation at every age and to design age-appropriate activities with graduated levels of difficulty. "The most reliable method for ensuring that project expectations and activities are age-appropriate is to involve the children themselves in defining the project's objectives and determining its activities" (Driskell, 2002). Hart (1997) maintained that there are always aspects in which all children, including those with disabilities or other special needs, can be involved and play valuable roles.

A number of site leaders felt optimistic that more opportunities for participation would exist when projects were further underway. Clearly, opportunities also exist in the preparatory stages of any project (Driskell, 2002; Hart, 1992), and greater efforts should be made to identify ways to engage young people now.

The ladder of participation (Hart, 1992, 1997), adapted for a gardening context, was shown to be a useful guide for increasing participation. However, site leaders' responses to the vertical nature of the ladder suggest that its implied hierarchical character poses problems both in determining where a program actually falls on the ladder of participation and the perception that the goal should be the top rung. Similar graphic representations of levels of children and youth participation such as "the dimensions of young people's participation" (Driskell, 2002) may prove a beneficial resource for leaders. Interviews pointed out the benefit of having examples specific to gardenbased projects, suggesting that any model may be more practically useful if put in the context of program area. More work could be done to create practical, concrete tools for assisting adult leaders in engaging children and 
youth in planning, design, and implementation of garden projects.

Greener Voices' successful efforts with the six sites in New York and Pennsylvania affirm the need to raise awareness about children and youth participation. Findings also point toward the need to continue creating opportunities for adults to develop strategies to engage children and youth as well as to overcome attitudinal and other barriers to increasing participation. In gardenbased programs, adults serve as facilitators, mentors, and educators and are critical players in enhancing participation opportunities for children and youth. Enhanced participation involves decision-making, teamwork, communication, and compromise, which can all lead to lifelong skills. As the number of children's gardens in schools and communities continues to grow, efforts to increase children and youth participation will be a key focus area in ensuring that design and use of these spaces is guided by their target audience.

Of particular interest is need for support to help young people adapt to new roles and obtain the knowledge that is needed for these new responsibilities. Children and youth may need to develop skills to help them participate at higher levels. For example, they can benefit from workshops and practice in facilitation, public speaking, collaboration, and evaluation methods. Furthermore, they may need to adjust their own thinking about what is possible for young people to do (O'Donoghue et al., 2002).

From what the authors learned in this project, it is clear that ongoing support of adult leaders needs to be considered in garden-based projects. Providing a network of support for leaders in this and related programs to increase children and youth participation in their sites and programs is an important component for their success. Opportunities for workshops and in-service training addressing the topic of youth-adult partnerships and ways to engage children and youth in planning, design, and implementation would likely be well received by adult leaders of garden- based projects. Given the constraints of time and funding, new ways of reaching out to adult volunteers and staff in garden-based learning programs needs to be explored. Taking opportunities to use the ladder of participation as a self-assessment measure, and involving children and youth in these assessment, and assessing barriers to participation are recommended to those leading similar program efforts. For those new to the participation arena, partnering with 4-H youth development or other youth-serving organizations can be an avenue through which workshops, in-service training, educational resource development, and guidance of such project efforts can take place.

Although this phase of Greener Voices focused on adult perspectives, more work needs to be done to explore the perspectives of children and youth in garden-based settings. Greener Voices children and youth surveys have been administered and are currently being analyzed.

\section{Literature cited}

Adams, E. and S. Ingham. 1998. Changing places: Children's participation in environmental planning. Children's Society, London.

Arnstein, S.R. 1969. Eight rungs on the ladder of citizen participation. J. Amer. Inst. Planners 35:216-224.

Driskell, D. 2002. Creating better cities with children and youth: A manual for participation. Earthscan Publ., UNESCO (United Nations Educational, Scientific, and Cultural Organization) Publ., Paris.

Eames-Sheavly, M. 1999. Sowing the seeds of success: Starting and sustaining a kids' gardening project in your community. National Gardening Assn., Burlington, Vt.

Hart, R. 1977. Children's experience of place. Irvington Publishers, N.Y.

Hart, R.A. 1992. Children's participation: From tokenism to citizenship. International Child Development Centre. United Nations Children's Fund, Florence, Italy.

Hart, R.A. 1997. Children's participation: The theory and practice of involving young citizens in community development and environmental care. United
Nations Children's Fund/Earthscan, N.Y. and London.

Heffernan, M. 1994. The children's garden project at River Farm. Children's Environ. 11:221-231.

Holden, C. and N. Clough. 1998. The child carried on the back does not know the length of the road: The teacher's role in assisting participation, p. 13-28. In: C. Holden and N. Clough (eds.). Children as citizens: Education for participation. Jessica Kingsley Publishers, London and Philadelphia.

Klemmer, C.D., T.M. Waliczek, and J.M. Zajicek. 2005. Growing minds: The effect of a school gardening program on the science achievement of elementary students. HortTechnology 15:448-452.

Lohr, V.I. and C.H. Pearson-Mims. 2005. Children's active and passive interactions with plants influence their attitudes and actions toward trees and gardening as adults. HortTechnology $15: 472-476$.

Moore, R.C. 1986. Childhood's domain: Play and place in child development. Croom Helm, London.

Moore, R. and D. Young. 1978. Childhood outdoors: Toward a social ecology of the landscape, p. 83-130. In: I. Alman and J. Wohlwill (eds.). Children and the environment. Plenum Press, N.Y.

O'Donoghue, J.L., B. Kirshner, and M. McLaughlin. 2002. Introduction: Moving youth participation forward. New Directions Youth Dev. 96:15-26.

Robinson, C.W. and J.M. Zajicek. 2005. Growing minds: The effects of a one-year school garden program on six constructs of life skills of elementary school children. HortTechnology 15:453-457.

Skelly, S.M. and J.M. Zajicek. 1998. The effect of an interdisciplinary garden program on the environmental attitudes of elementary school students. HortTechnology 8:579-583.

Waliczek, T.M. and J.M. Zajicek. 1999. School gardening: Improving environmental attitudes of children through hands-on learning. J. Environ. Hort. 17:180-184.

Willow, C. 2002. Participation in practice: Children and young people as partners in change. Children's Society, London.

Winter, M.D. 1997. Children as fellow citizens: Participation and commitment. Radcliffe Medical Press Ltd., N.Y. 